\title{
Blind placement of postpyloric feeding tubes at the bedside in intensive care
}

\author{
Qianwen Wang ${ }^{\dagger}$, Yongbo Xuan ${ }^{\dagger}$, Cuiping Liu ${ }^{\dagger}$, Mei Lu, Zhanguo Liu* ${ }^{*}$ and Ping Chang*
}

Postpyloric feeding is recommended for those who cannot tolerate gastric enteral nutrition or who are at high risk of aspiration [1-3]. This approach can reduce respiratory and gastrointestinal complications and achieve nutritional goals earlier and more effectively. A large cohort study that investigated the nutritional support habits in the intensive care unit (ICU) revealed that the nasojejunal tube was only applied in $5.5 \%$ of the patients [4]. The lack of effective transpyloric placement methods may be a critical reason for the low application of nasojejunal tube. Various blind techniques for postpyloric feeding tube placement have been applied to clinical practice. Unfortunately, no unified opinion exists for these techniques. Several studies state that the success rate of blind placement ranged from $35 \%$ to $100 \%$. Consequently, blind placements using the Corpak postpyloric feeding tube may be another alternative approach. Andrew et al. reported that the best success rate was $90 \%$ [5]. However, only 20 patients with gastric ileus were enrolled in their study. This retrospective study evaluated the safety and efficiency of blind bedside postpyloric placement and investigated the potential risk factors influencing the placement in critically ill patients.

The study protocol was approved by Zhujiang Hospital Ethical Committees (2020-KY-064-01). Patients who underwent blind bedside insertion of Corpak postpyloric feeding tube between December 2016 and January 2020 were included in Department of Critical Care Medicine. This operation was performed by experienced

*Correspondence: zhguoliu@163.com; changp963@163.com

${ }^{\dagger}$ Qianwen Wang, Yongbo Xuan and Cuiping Liu contributed equally to this work

Department of Critical Care Medicine, Zhujiang Hospital, Southern Medical University, 253 Gongye Middle Avenue, Haizhu District,

Guangzhou 510280, Guangdong, China head nurses or nurse leaders. For patients without any contraindications, $10 \mathrm{mg}$ of metoclopramide was administrated before the intubation. Upper abdominal radiography was requested to confirm the position of the tube tip within $24 \mathrm{~h}$. The primary outcome was the success rate of placement. The success rates of post-third portion of the duodenum (D3), post-fourth portion of the duodenum (D4), proximal jejunum placement, insertion length, time for insertion, number of attempts, and the possible risk factors for tube placement failure were secondary outcomes. Safety endpoints were major tube-associated and metoclopramide-related adverse events.

The postpyloric placement was achieved in $83.7 \%$ $(236 / 282)$ of patients, with $69.9 \%(197 / 282)$ of the patients

Table 1 The primary outcomes and secondary efficacy outcomes

\begin{tabular}{ll}
\hline Outcomes & $\begin{array}{l}\text { Value in tota } \\
(\boldsymbol{n}=\mathbf{2 8 2})\end{array}$ \\
\hline $\begin{array}{l}\text { Primary outcomes } \\
\text { Post-pyloric placement }\end{array}$ & \\
Secondary outcomes & $236(83.7 \%)$ \\
Placed at D3 or beyond & \\
Placed at D4 or beyond & \\
Placed at the proximal jejunum & $194(68.8 \%)$ \\
Time to insertion, min & $167(59.2 \%)$ \\
Number of attempts & $30(20-30)$ \\
Length of insertion (cm) & $1(1-2)$ \\
\hline
\end{tabular}

According to whether the variables comply with the normal distribution, quantitative variables are presented as mean $\pm S D$ or median (IQR) as appropriate and qualitative variables as numbers (percentage)

a Post-pyloric placement, reaching the first portion of the duodenum or beyond

${ }^{b} \mathrm{D} 3$ is the third portion of the duodenum

${ }^{\mathrm{C}} \mathrm{D} 4$ is the forth portion of the duodenum original author(s) and the source, provide a link to the Creative Commons licence, and indicate if changes were made. The images or other third party material in this article are included in the article's Creative Commons licence, unless indicated otherwise in a credit line to the material. If material is not included in the article's Creative Commons licence and your intended use is not permitted by statutory regulation or exceeds the permitted use, you will need to obtain permission directly from the copyright holder. To view a copy of this licence, visit http://creativecommons.org/licenses/by/4.0/. The Creative Commons Public Domain Dedication waiver (http://creativeco mmons.org/publicdomain/zero/1.0/) applies to the data made available in this article, unless otherwise stated in a credit line to the data. 


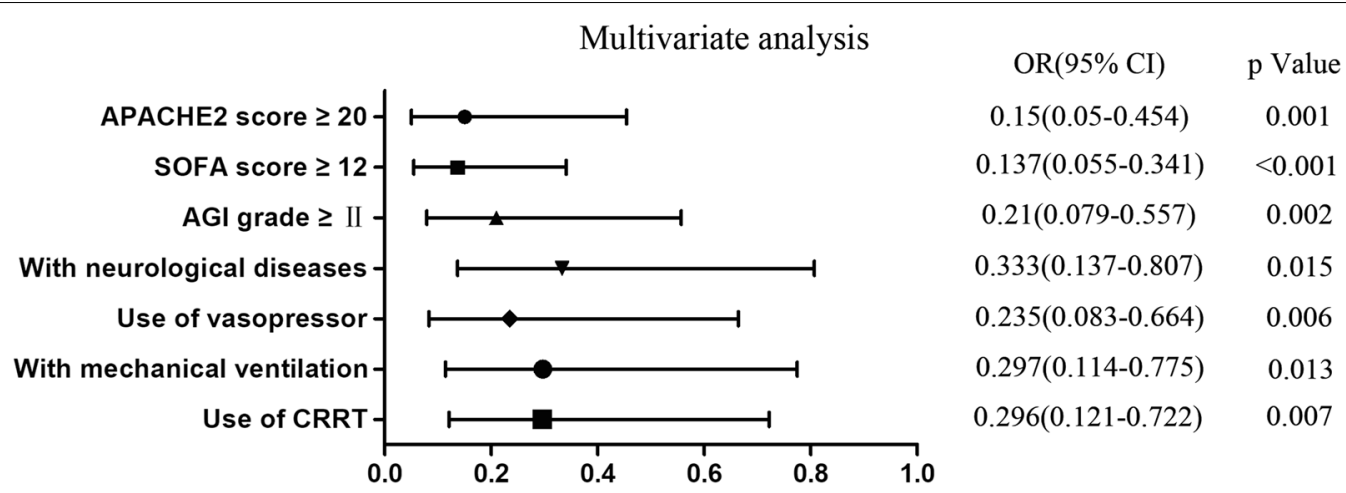

Fig. 1 Multivariate logistic regression analysis of factors for the success of postpyloric placement. $O R$ odds ratio, $C /$ confidence interval; $P<0.05$ was considered to be statistically significant

completed in the first attempt. The success rates of postD3, post-D4, and proximal jejunum placement were $68.8 \%$, $59.2 \%$, and $25.9 \%$, respectively. The mean length of insertion was $101.4 \mathrm{~cm}$ and the median time to insertion was $30 \mathrm{~min}$, with 1.0 median number of attempts. These data are summarized in Table 1 . Logistic regression analysis identified the use of vasopressor, patients with neurological diseases, Acute Physiology and Chronic Health Evaluation (APACHE) II score $\geq 20$, Sequential Organ Failure Assessment (SOFA) score $\geq 12$, Acute Gastrointestinal (AGI) grade $\geq$ II, and with mechanical ventilation or continuous renal replacement therapy (CRRT) as independent risk factors influencing the success rate of placement (Fig. 1). The presence of above factors indicated the critical condition of the patients and the impaired state of their gastrointestinal function. Therefore, these patients always showed a lower success rate. On the contrary, patients without the above risk factors were more likely to show successful outcomes. The adverse event incidence in this study was $2.8 \%$. Fortunately, no severe adverse events occurred. Nasal mucosa bleeding was the most frequent major tube-associated adverse events with an incidence rate of $1.8 \%$. However, the metoclopramide-related adverse event was not observed.

In conclusion, blind placement of Corpak postpyloric feeding tubes at the bedside was considered to be safe and effective for critically ill patients, and the results of the current study further confirmed that all the aforementioned factors were independent risk factors and the findings of this may provide evidence for tailored therapy. Thus, this technique may facilitate the establishment of postpyloric feeding in the ICU.

\section{Abbreviations}

APACHE II: Acute physiology and chronic health evaluation II; SOFA: Sequential organ failure assessment; AGI: Acute gastrointestinal injury; CRRT: Continuous renal replacement therapy; OR: Odds ratio; Cl: Confidence interval.

\section{Acknowledgements}

None.

\section{Authors' contributions}

ZGL conceived of the study, and participated in its design and coordination and helped to revised the manuscript. PC participated in the design of the study and revised the manuscript. QWW participated in the design of the study and performed the statistical analysis. CPL and YBX collected the data and wrote the first draft of the manuscript. ML collected the data. All authors read and approved the final manuscript.

\section{Funding}

This work is supported by the National Natural Science Foundation of China (Grant 81971859 and 81971883), the Natural Science Foundation of Guangdong Province, China (Grant 2019A1515011856), and the Clinical Research Startup Program of Southern Medical University by the High-level University Construction Funding of Guangdong Provincial Department of Education (Grant LC2019ZD014).

\section{Availability of data and materials}

The datasets generated and analyzed during the current study are available from the corresponding author on reasonable request.

\section{Declarations}

Ethics approval and consent to participate

This study was reviewed and approved by Zhujiang Hospital Ethical Committees (2020-KY-064-01) with waiver of written consent.

\section{Consent for publication}

Not applicable.

\section{Competing interests}

The authors declare that they have no competing interests.

Received: 3 February 2021 Accepted: 27 April 2021

Published online: 11 May 2021

\section{References}

1. Taylor BE, Mcclave SA, Martindale RG, Warren MM, Johnson DR, Braunschweig C, et al. Guidelines for the provision and assessment of nutrition support therapy in the adult critically III patient: Society of Critical Care Medicine (SCCM) and American Society for Parenteral and Enteral Nutrition (A.S.P.E.N.). Crit Care Med. 2016;44:390-438.

2. Kreymann KG, Berger MM, Deutz NE, Hiesmayr M, Jolliet P, Kazandjiev $G$, et al. ESPEN guidelines on enteral nutrition: intensive care. ClinNutr. 2006;25:210-23. 
3. Reintam BA, Starkopf J, Alhazzani W, Berger MM, Casaer MP, Deane AM, et al. Early enteral nutrition in critically ill patients: ESICM clinical practice guidelines. Intensive Care Med. 2017;43:380-98.

4. Bendavid I, Singer P, Theilla M, Themessl-Huber M, Sulz I, Mouhieddine M, et al. NutritionDay ICU: a 7 year worldwide prevalence study of nutrition practice in intensive care. ClinNutr. 2017;36:1122-9.

5. Lee AJ, Eve R, Bennett MJ. Evaluation of a technique for blind placement of post-pyloric feeding tubes in intensive care: application in patients with gastric ileus. Intensive Care Med. 2006;32:553-6.

\section{Publisher's Note}

Springer Nature remains neutral with regard to jurisdictional claims in published maps and institutional affiliations.
Ready to submit your research? Choose BMC and benefit from:

- fast, convenient online submission

- thorough peer review by experienced researchers in your field

- rapid publication on acceptance

- support for research data, including large and complex data types

- gold Open Access which fosters wider collaboration and increased citations

- maximum visibility for your research: over $100 \mathrm{M}$ website views per year

At BMC, research is always in progress.

Learn more biomedcentral.com/submissions 